\title{
Cystatin C, COVID-19 severity and mortality: a systematic review and meta-analysis
}

\author{
Angelo Zinellu ${ }^{1} \cdot$ Arduino A. Mangoni ${ }^{2,3}$
}

Received: 29 March 2021 / Accepted: 6 August 2021 / Published online: 14 August 2021

(C) Italian Society of Nephrology 2021

\begin{abstract}
Background Combined markers of renal dysfunction and inflammation, e.g., cystatin C, might assist with risk stratification and clinical decisions in patients with coronavirus disease 19 (COVID-19). We conducted a systematic review and metaanalysis with meta-regression of serum cystatin C in COVID-19.

Methods We searched PubMed, Web of Science and Scopus, between January 2020 and February 2021, for studies reporting serum cystatin C concentrations, measures of clinical severity and survival outcomes in hospitalized COVID-19 patients (PROSPERO registration number: CRD42021245295).

Results Thirteen studies in 2510 COVID-19 patients, 1972 with low severity or survivor status and 538 with high severity or non-survivor status during follow up, were included in the meta-analysis. The pooled results showed that serum cystatin $\mathrm{C}$ concentrations were higher in patients with high disease severity or non-survivor status (standard mean deviation, SMD, $1.71,95 \%$ CI 0.95 to $2.46, p<0.001)$. Extreme between-study heterogeneity was observed $\left(I^{2}=97.5 \%, p<0.001\right)$. Sensitivity analysis, performed by sequentially removing each study and re-assessing the pooled estimates, showed that the magnitude and direction of the effect size was not substantially modified. The Begg's and Egger's $t$ tests did not show publication bias. In meta-regression, the SMD of serum cystatin C was not associated with age, proportion of males, C-reactive protein, neutrophils, lymphocytes, aspartate aminotransferase, alanine aminotransferase, albumin, creatinine, creatine kinase-MB, lactate dehydrogenase, and proportion of patients with diabetes or hypertension.
\end{abstract}

Conclusions Higher concentrations of serum cystatin C were associated with higher COVID-19 severity and mortality.

Arduino A. Mangoni

arduino.mangoni@flinders.edu.au

1 Department of Biomedical Sciences, University of Sassari, Sassari, Italy

2 Discipline of Clinical Pharmacology, College of Medicine and Public Health, Flinders University and Flinders Medical Centre, Bedford Park, SA 5042, Australia

3 Department of Clinical Pharmacology, Flinders Medical Centre, Southern Adelaide Local Health Network, Adelaide, Australia 


\section{Graphic abstract}

\begin{tabular}{|c|c|c|c|c|c|}
\hline \multicolumn{3}{|l|}{ Study } & \multirow{2}{*}{$\begin{array}{l}\text { Severe disease or } \\
\text { poor outcome } \\
\mathrm{N}, \text { mean, (SD) }\end{array}$} & \multirow{2}{*}{$\begin{array}{l}\text { Mild disease or } \\
\text { good outcome } \\
\mathrm{N} \text {, mean, (SD) }\end{array}$} & \multirow{2}{*}{$\begin{array}{l}\% \\
\text { Weigh }\end{array}$} \\
\hline Name & & $\operatorname{SMD}(95 \% \mathrm{Cl})$ & & & \\
\hline Cao J et al. & $\begin{array}{r}1 \\
+ \\
+\end{array}$ & $1.63(1.07,2.18)$ & $17,1.66(.97)$ & $102, .98(.23)$ & 7.12 \\
\hline Deng $M$ et al. & $+i$ & $0.63(-0.01,1.27)$ & $12,1.1(.24)$ & $53, .89(.35)$ & 7.04 \\
\hline LiY et al. & 1 & $1.24(0.80,1.69)$ & $37,1.07(.3)$ & $64, .8(.15)$ & 7.22 \\
\hline Tang $Y$ et al. & + & $3.85(3.24,4.45)$ & $60,1.3(.13)$ & $60, .93(.04)$ & 7.07 \\
\hline Wang $C$ et al. & ו & $1.30(0.55,2.06)$ & $10,2.33(2.5)$ & $35, .81(.26)$ & 6.90 \\
\hline Wang J et al. & +1 & $0.45(0.17,0.74)$ & $53,1.06(.41)$ & $509, .95(.22)$ & 7.33 \\
\hline Wu C et al. (a) & +1 & $0.74(0.45,1.03)$ & $84,1(.3)$ & $117, .83(.16)$ & 7.32 \\
\hline Wu Cet al. (b) & +1 & $0.53(0.09,0.96)$ & $44,1.11(.43)$ & $40, .92(.26)$ & 7.23 \\
\hline Xiang $\mathrm{HX}$ et al. & + & $0.19(-0.22,0.59)$ & $29.84(.16)$ & $125, .81(.16)$ & 7.25 \\
\hline Yang Z et al. & I & $\rightarrow 9.51(8.67,10.36)$ & $71,1.01(.04)$ & $202,8(.01)$ & 6.78 \\
\hline Yao $Q$ et al. & $\rightarrow$ & $1.20(0.58,1.82)$ & $12,2.55(2.63)$ & $96,1.44(.39)$ & 7.05 \\
\hline Zhang $Q$ et al. & $\rightarrow !$ & $0.85(0.36,1.35)$ & $27,1.17(.3)$ & $47, .93(.27)$ & 7.18 \\
\hline Zhang XP et al. & + & $1.54(1.10,1.99)$ & $22,1.55(.91)$ & $410,1.05(.26)$ & 7.22 \\
\hline Zhao C et al. & +1 & $0.73(0.41,1.05)$ & $60,1.35(.56)$ & $112,1.07(.24)$ & 7.30 \\
\hline Overall $(1-$ squared $=97.5 \%, p=0.000)$ & \langle & $1.71(0.95,2.46)$ & 538 & 1972 & 100.00 \\
\hline NOTE: Weights are from random effects analysis & 1 & & & & \\
\hline
\end{tabular}
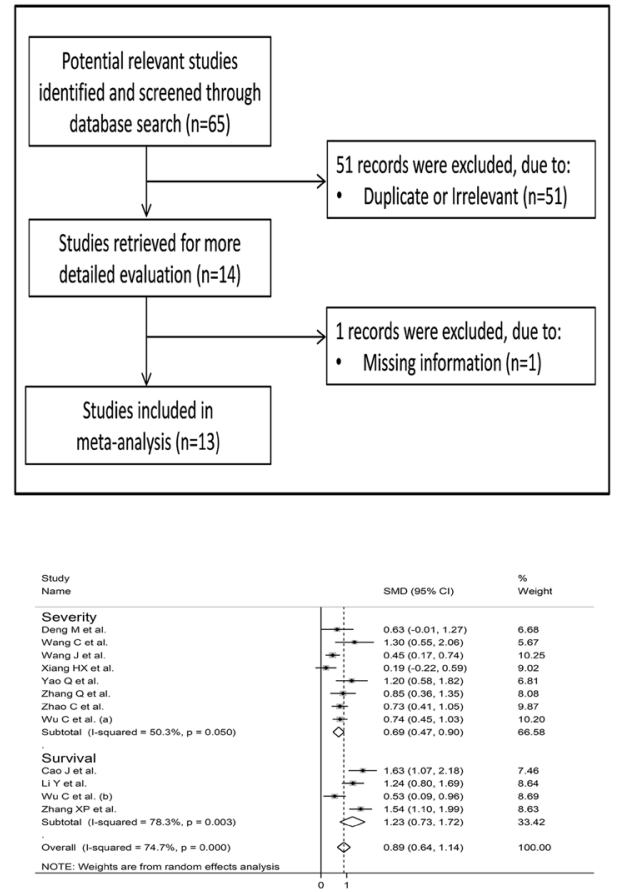

Keywords Serum cystatin C · COVID-19 severity $\cdot$ Mortality

\section{Introduction}

A number of clinical and demographic factors and biomarkers have shown significant associations with coronavirus disease 19 (COVID-19) severity, based on clinical presentation, imaging findings, or need for intensive care unit (ICU) admission, and survival outcomes [1, 2]. In terms of biomarkers, the excessive activation of inflammatory and oxidative stress pathways observed in severe COVID-19 has prompted the assessment of the diagnostic and prognostic role of C-reactive protein, white blood cell components, procalcitonin, ferritin, prealbumin, and serum amyloid A [3-7]. Additionally, patients with more severe forms of the disease often experience extrapulmonary abnormalities affecting different organs and systems, e.g., cardiovascular, haematological, gastrointestinal, and neurological [8]. Another key organ likely to be involved in COVID-19 is the kidney, with a reported prevalence of acute kidney injury (AKI) in hospitalized patients as high as $43 \%[9,10]$. While the exact mechanisms responsible for the onset and the development of renal dysfunction are not fully established, studies have reported positive staining of tubules with antigens of severe acute respiratory syndrome coronavirus 2 (SARS-CoV-2), the agent responsible for COVID-19, and complement components, the presence of viral particles in tubular epithelial cells and podocytes, and the isolation of
SARS-CoV-2 in urine [9]. Other investigations have demonstrated the presence of acute tubular injury, glomerular fibrin thrombi, indicating endothelial dysfunction and coagulopathy, and acute tubular necrosis [11-15]. Notably, the presence of COVID-19-associated AKI independently predicts adverse clinical outcomes [10]. The relatively frequent occurrence of renal dysfunction in patients with COVID-19 suggests that renal biomarkers might assist with early risk stratification, monitoring and management in this group [10]. However, the availability of biomarkers that are able to reflect not only the early presence of kidney dysfunction but also other abnormal processes, e.g., systemic inflammation, oxidative stress, and cytokine storm, might be particularly useful in this context. Cystatin C is a low-molecular-weight protein that is a member of the cystatin superfamily of cysteine protease inhibitors. Cystatin $\mathrm{C}$ is widely distributed in different organs and tissues and, in view of its relatively small molecular weight and easy detection, is also used as a marker of glomerular filtration rate. Unlike other renal biomarkers, e.g., serum creatinine, cystatin $\mathrm{C}$ is less susceptible to biological interference and more sensitive to early deterioration in renal function [16-18]. Furthermore, there is increasing evidence that cystatin $\mathrm{C}$ is associated with various immune responses to exogenous and endogenous antigens and that its encoding gene is regulated by a number of cytokines during inflammation and infection [19]. In turn, cystatin $\mathrm{C}$ can exert several immunomodulatory functions by 
controlling the activity of cysteine proteases and other mechanisms. This has led some authors to propose its prognostic use in inflammatory disorders [19, 20]. Given that the assessment of serum cystatin C in COVID-19 patients might provide useful information regarding the combined presence of excess systemic inflammation and kidney dysfunction, we sought to investigate the clinical role of this biomarker by conducting a systematic review and meta-analysis of studies reporting serum cystatin $\mathrm{C}$ concentrations in patients with different degrees of disease severity and survival status during followup. In particular, we speculated that patients with severe disease and/or reduced survival had higher concentrations of serum cystatin $\mathrm{C}$ when compared to those with milder disease and/or favourable outcomes. A meta-regression analysis was also performed to investigate possible associations between the effect size of the between-group differences in serum cystatin $\mathrm{C}$ concentrations, clinical and demographic factors, and markers of inflammation and organ damage.

\section{Materials and methods}

\section{Search strategy and study selection}

A literature search was conducted, using the terms "cystatin C" and "coronavirus disease 19" or "COVID-19", in the electronic databases PubMed, Web of Science and Scopus, from January 2020 to February 2021, to identify peerreviewed studies reporting serum cystatin $\mathrm{C}$ concentrations in COVID-19 patients (PROSPERO registration number: CRD42021245295). The references of the retrieved articles were also searched to identify additional studies. Eligibility criteria for inclusion were as follows: (a) reporting continuous data on serum cystatin C concentrations in COVID-19 patients, (b) investigating COVID-19 patients with different degrees of disease severity and/or survival status during follow up, (c) adult patients, (d) English language, and (e) full-text article available. Two investigators independently screened all abstracts. If relevant, they independently reviewed the full-text articles. The Newcastle-Ottawa scale

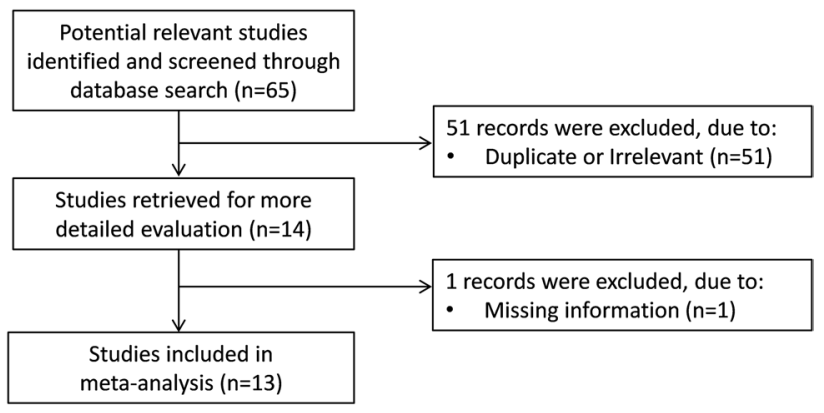

Fig. 1 Flow chart of study selection was used to assess study quality. A score of $\geq 6$ indicated high quality [21].

\section{Statistical analysis}

Standardized mean differences (SMD) and $95 \%$ confidence intervals (CIs) were calculated to build forest plots of continuous data and evaluate differences in cystatin $\mathrm{C}$ concentrations between COVID-19 patients with low vs. high severity or survivor vs. non-survivor status during follow up. A $p$ value $<0.05$ was considered statistically significant. If studies reported concentrations as median and interquartile range (IQR), the corresponding mean and standard deviation were estimated [22]. When individual studies described more than two patient groups (e.g., mild, moderate, severe, and critical illness) the mild/moderate and the severe/critical were combined. The mean and standard deviation of the new combined group was calculated by weighting for the sample size of the original groups. The Q-statistic was used to assess the heterogeneity of the SMD across studies (the significance level was set at $p<0.10$ ) and to select the model, random vs. fixed, to be used. Inconsistency across studies was evaluated using the $I^{2}$ statistic: $I^{2}<25 \%$, no heterogeneity; $I^{2}$ between 25 and 50\%, moderate heterogeneity; $I^{2}$ between 50 and $75 \%$, large heterogeneity; and $I^{2}>75 \%$, extreme heterogeneity $[23,24]$. Sensitivity analyses were conducted to evaluate the influence of individual studies on the overall effect size using the leave-one-out method [25]. The possible presence of publication bias was assessed using the Begg's adjusted rank correlation test and the Egger's regression asymmetry test at the $p<0.05$ level of significance [26, 27]. The Duval and Tweedie "trim-and-fill" procedure was also used to further test and correct for the possible presence of publication bias. This method recalculates a pooled SMD by incorporating the hypothetical missing studies as though they existed, to augment the observed data and the symmetry of the funnel plot [28]. To explore possible contributors to the between-study variance, we further investigated in univariate meta-regression analysis the associations, expressed as $t$ values, between the SMD and the following parameters, expressed as summary statistics in means or medians: age, proportion of males, study endpoint, inflammatory markers (C-reactive protein, neutrophils, lymphocytes), liver function (aspartate aminotransferase, alanine aminotransferase, albumin), renal function (creatinine), myocardial damage (creatine kinase-MB), multi-tissue damage (lactate dehydrogenase), proportion of patients with diabetes and proportion of patients with hypertension. Sub-group analysis was conducted to investigate possible differences in SMD and heterogeneity according to specific endpoints, i.e., disease severity vs. survival status. Statistical analyses were performed using Stata 14 (STATA Corp., College Station, TX, USA). 


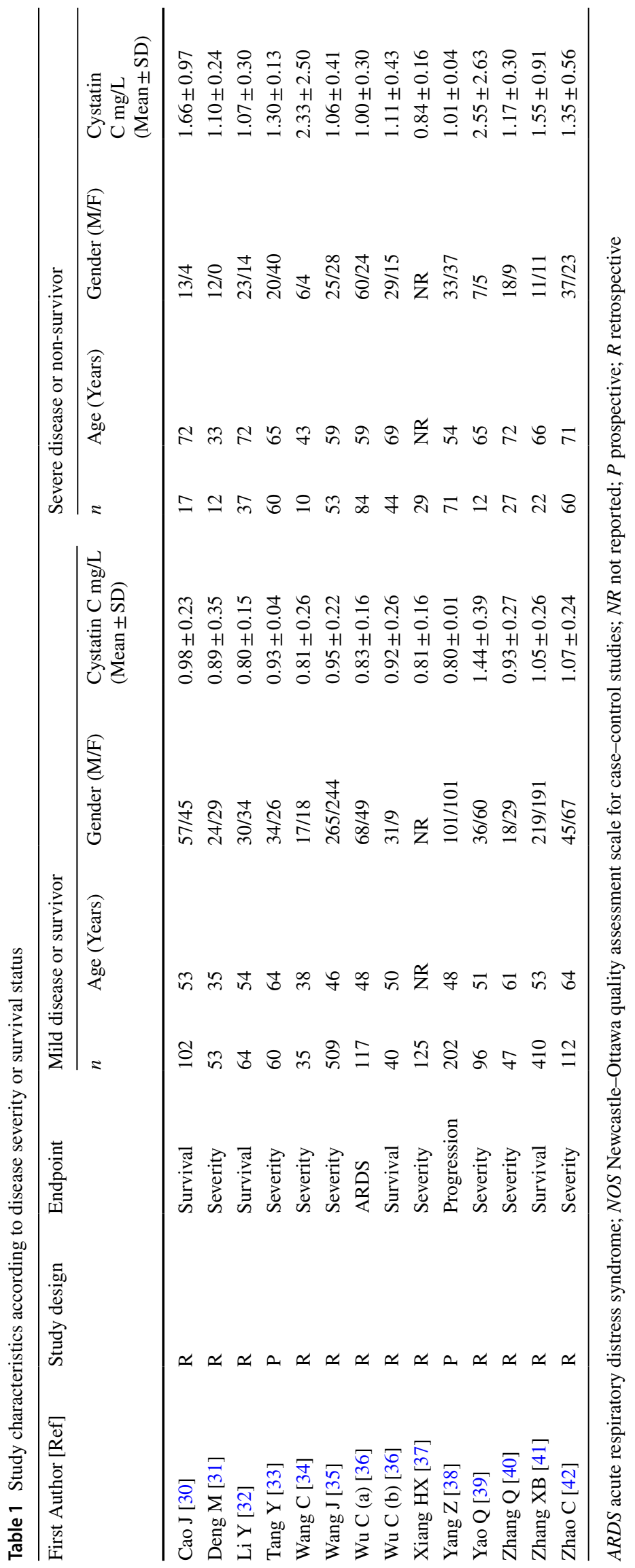




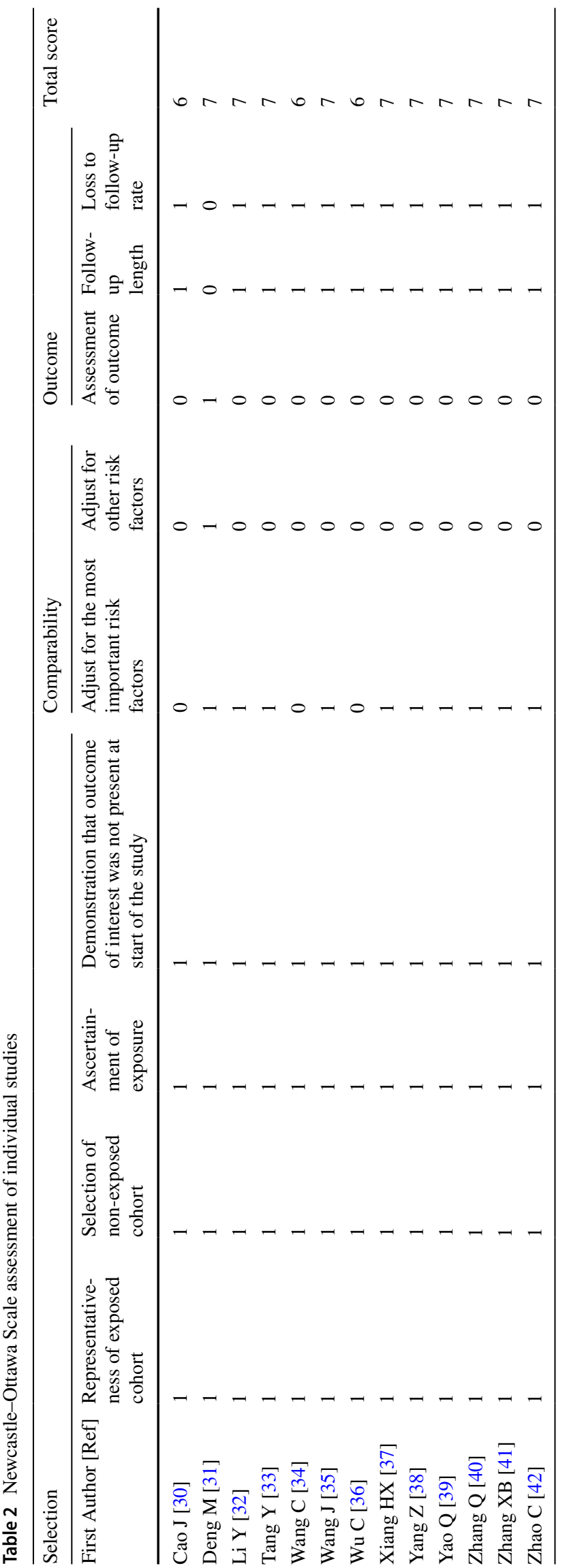

We fully complied with the PRISMA statement regarding the reporting of systematic reviews and meta-analyses [29].

\section{Results}

\section{Study selection}

We initially identified 65 studies. Of them, 51 were excluded after the first screening because they were either duplicates (same article identified in different databases) or irrelevant (not fulfilling the inclusion criteria). After a full-text revision of the remaining 14 articles, one was excluded because of missing information, leaving 13 studies for further analysis (Fig. 1) [30-42]. The characteristics of these studies, all conducted in China, are described in Tables 1,2. A total of 2510 COVID-19 patients were assessed, 1972 (51\% males, mean age 51 years) with low severity or survivor status and 538 (58\% males, mean age 59 years) with high severity or non-survivor status. Eleven studies were retrospective [30-32, 34-37, 39-42], whilst the remaining two were prospective $[33,38]$. Endpoints included disease severity based on current clinical guidelines (8 studies) [31, 33-35, 37, 39, $40,42]$, disease progression (one study) [38] and occurrence of acute respiratory distress syndrome (ARDS) (one study) [36], and survival status (4 studies) [30, 32, 36, 41]. Only two studies reported the presence of AKI [32, 39]. All studies reported cystatin $\mathrm{C}$ concentrations measured on admission, except one study that reported mean values throughout the hospitalization [34].

\section{Meta-analysis}

The overall SMD in cystatin C concentrations between COVID-19 patients with low vs. high severity or survivor vs. non-survivor status is reported in Fig. 2. In 12 studies, patients with high severity or non-survivor status had higher cystatin $\mathrm{C}$ concentrations when compared to those with low severity or survivor status (mean difference range, 0.19-9.51) [31-37]. The pooled results confirmed that cystatin $\mathrm{C}$ concentrations were higher in patients with high severity or non-survivor status (SMD $=1.71,95 \%$ CI $0.95-2.46$, $p<0.001$ ) (Fig. 2). Extreme heterogeneity between studies was observed $\left(I^{2}=97.5 \%, p<0.001\right)$.

Sensitivity analysis, performed by sequentially removing individual studies and re-assessing the pooled estimates, showed that the magnitude and direction of the effect size was not substantially modified (effect size range, between 1.12 and 1.83) (Fig. 3). However, the funnel plot showed a distortive effect of the two prospective studies (Fig. 4) [33, 38]. Removing these studies attenuated both the effect size $(\mathrm{SMD}=0.89,95 \% \mathrm{CI}, 0.64-1.14, p<0.001)$ and the magnitude of the heterogeneity $\left(I^{2}=74.7 \%, p<0.001\right)$. 


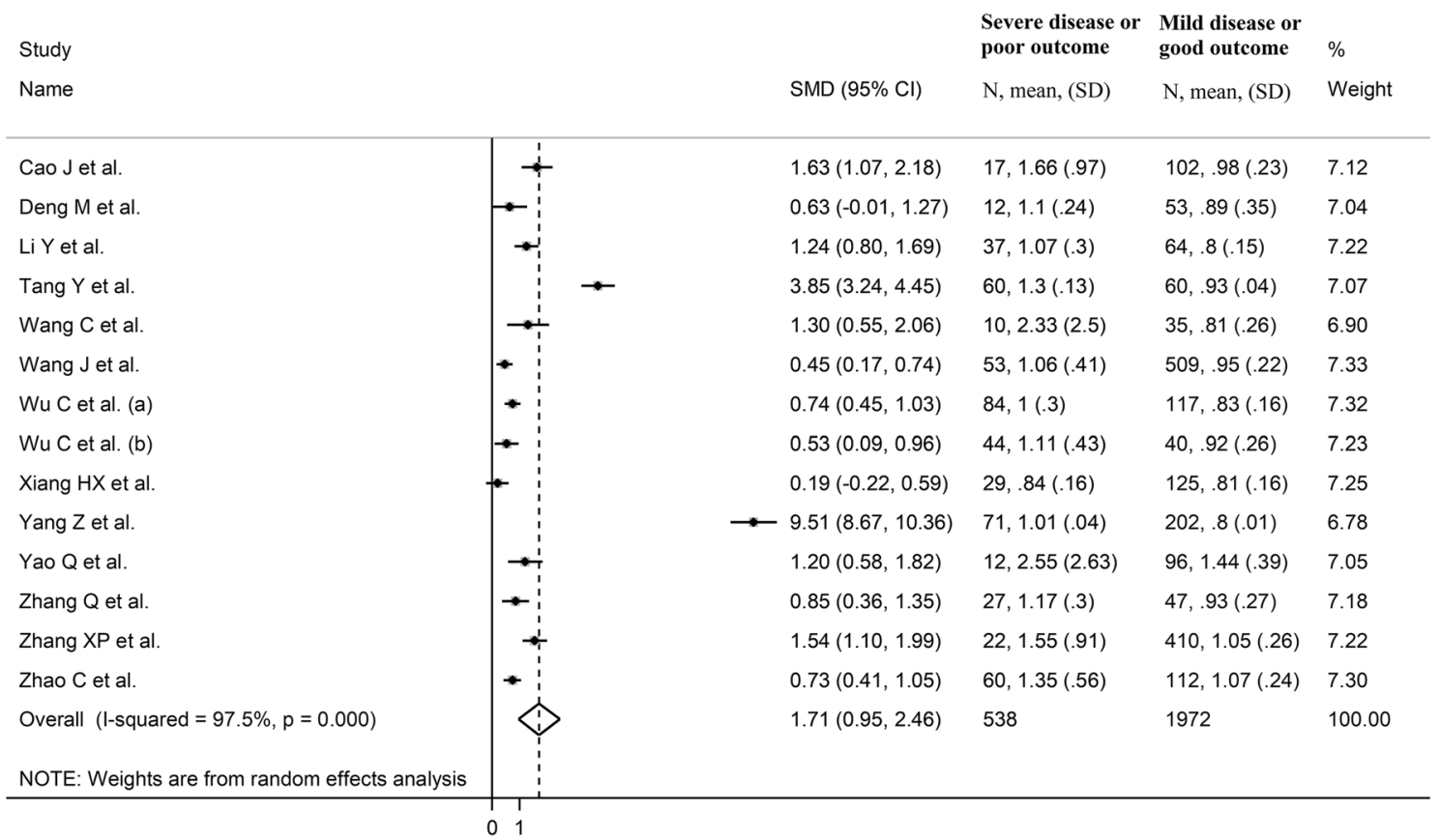

Fig. 2 Forest plot of selected studies

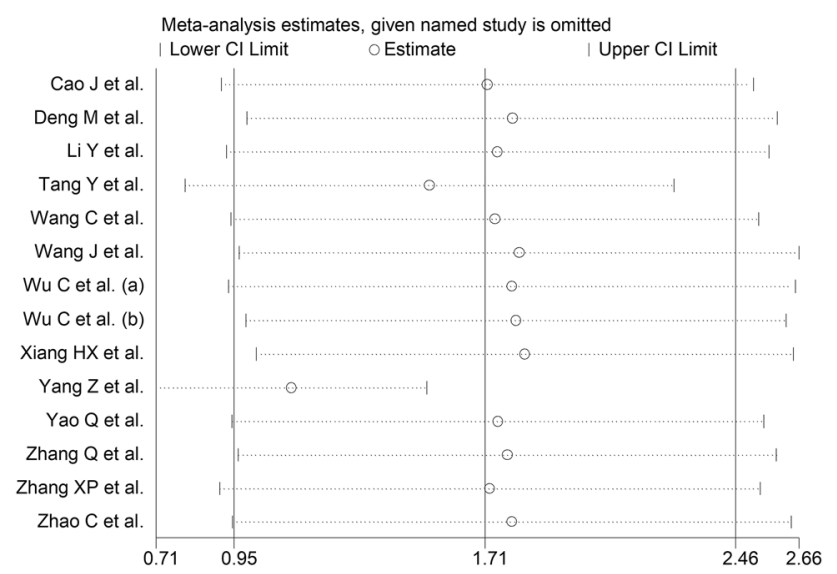

Fig. 3 Sensitivity analysis of the association between cystatin $\mathrm{C}$ and COVID-19 disease. The influence of individual studies on the overall standardized mean difference $(S M D)$ is shown. The middle vertical axis indicates the overall SMD, and the two vertical axes indicate the $95 \%$ confidence intervals $(C I s)$. The hollow circles represent the pooled SMD when the remaining study is omitted from the metaanalysis. The two ends of each broken line represent the 95\% CI

Analysis of the 11 remaining studies did not show publication bias (Begg's test, $p=0.15$; Egger's test, $p=0.10$ ). The trim-and-fill method identified four potential missing studies to add to the left of the funnel plot to ensure symmetry (Fig. 5). This resulted in a reduced effect size ( $\mathrm{SMD}=0.64$, 95\% CI 0.36-0.92, $p<0.001)$.

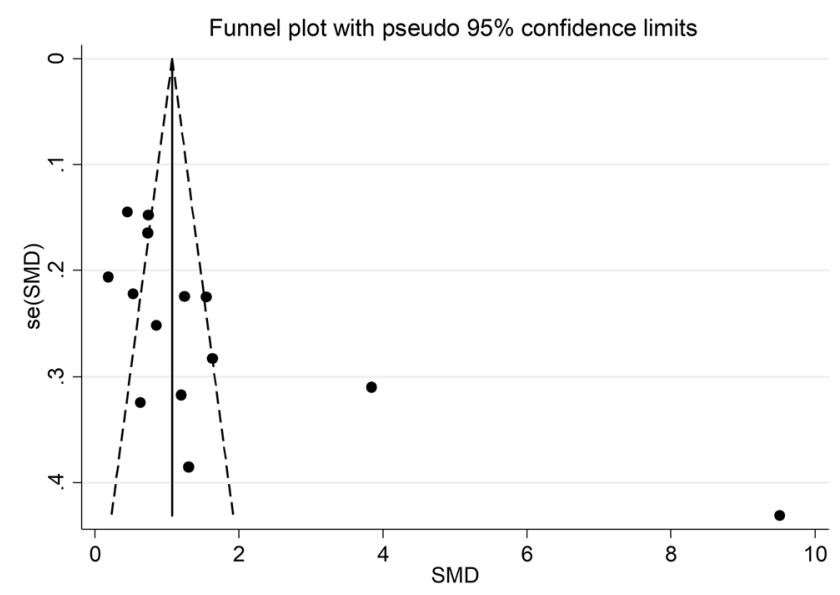

Fig. 4 Funnel plot of studies investigating low vs. high severity or survivor vs. non-survivor status

\section{Meta-regression}

There were no associations between the SMD and age $(t=0.76, p=0.47)$, proportion of males $(t=0.26, p=0.80)$, C-reactive protein $(t=-0.76, p=0.47)$, neutrophils $(t=1.65, p=0.15)$, lymphocytes $(t=-0.38, p=0.72)$, aspartate aminotransferase $(t=0.25, p=0.81)$, alanine aminotransferase $(t=-0.26, p=0.80)$, albumin $(t=-1.69$, $p=0.14)$, creatinine $(t=0.57, p=0.59)$, creatine kinaseMB $(t=0.41, p=0.70)$, lactate dehydrogenase $(t=1.37$, $p=0.22)$, proportion of patients with diabetes $(t=1.08$, 


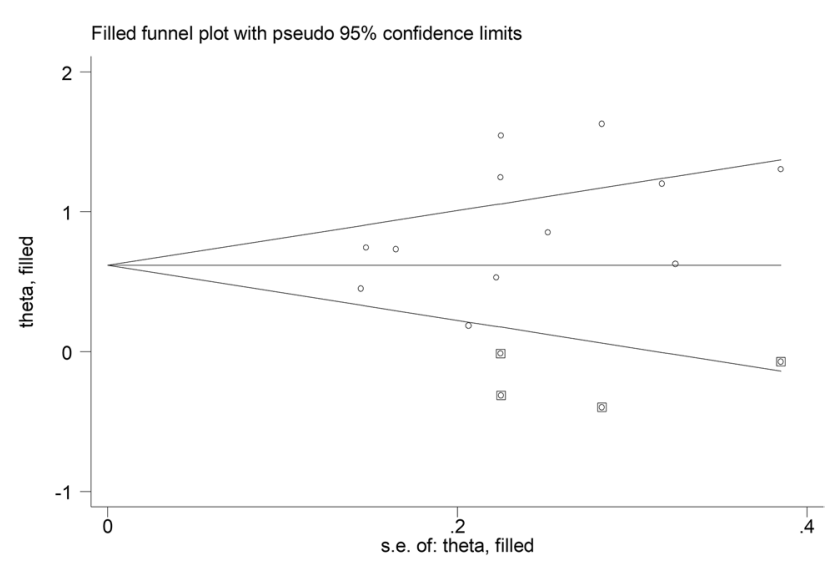

Fig. 5 Funnel plot of studies investigating low vs. high severity or survivor vs. non-survivor status after trimming and filling. Dummy studies and genuine studies are represented by enclosed circles and free circles, respectively

$p=0.31$ ), or proportion of patients with hypertension $(t=1.43, p=0.19)$.

In addition, sub-group analysis according to the specific endpoint evaluated, i.e., disease severity or survival status, did not show any differences $(t=2.10, p=0.06)$ between the effect size in studies evaluating disease severity (SMD $=0.69,95 \%$ CI $0.47-0.90, p<0.001)$ and those assessing survival (SMD $=1.23$, 95\% CI $0.73-1.72$, $p<0.001$ ) (Fig. 6), with a relatively lower between-study heterogeneity in the former $\left(I^{2}=50.3 \%\right.$ vs. $\left.I^{2}=78.3 \%\right)$.

\section{Discussion}

The results of this systematic review and meta-analysis support a potential clinical role of cystatin $\mathrm{C}$ in the evaluation of patients with COVID-19. Specifically, serum cystatin $\mathrm{C}$ concentrations were associated with COVID-19 severity and mortality. The magnitude of the observed SMD value, 1.71, indicates the presence of a large effect size [43]. Although the between-group heterogeneity was extreme the sequential removal of individual studies did not substantially affect the overall SMD value. While the funnel plot identified a distortive effect of two studies, their removal attenuated the effect size, but not the significance of the between-group difference, and the magnitude of the heterogeneity. Furthermore, no publication bias was observed.

The cysteine protease inhibitor cystatin $\mathrm{C}$ has been studied for a relatively long time as a marker of renal function, specifically glomerular filtration rate. In contrast with the traditional biomarker creatinine, cystatin $\mathrm{C}$ is less influenced by differences in muscle mass and other factors such as age and changes in diet [17, 44, 45]. In support of these characteristics, cystatin $\mathrm{C}$ has been shown to have superior sensitivity to changes in borderline renal function, and to rise earlier than creatinine in different patient groups, e.g., transplant, surgical, cardiovascular, and diabetic [18, 46, 47]. While higher serum concentrations of cystatin $\mathrm{C}$ are likely to reflect the presence of kidney dysfunction, e.g., AKI, in patients with COVID-19, they might also be a marker of the excessive systemic inflammatory and pro-oxidant state that characterizes this group [3]. An increasing number of studies have provided convincing evidence that cystatin $\mathrm{C}$ plays an
Fig. 6 Forest plot of studies examining cystatin $\mathrm{C}$ serum concentrations in patients with COVID-19 according to disease severity or survival status

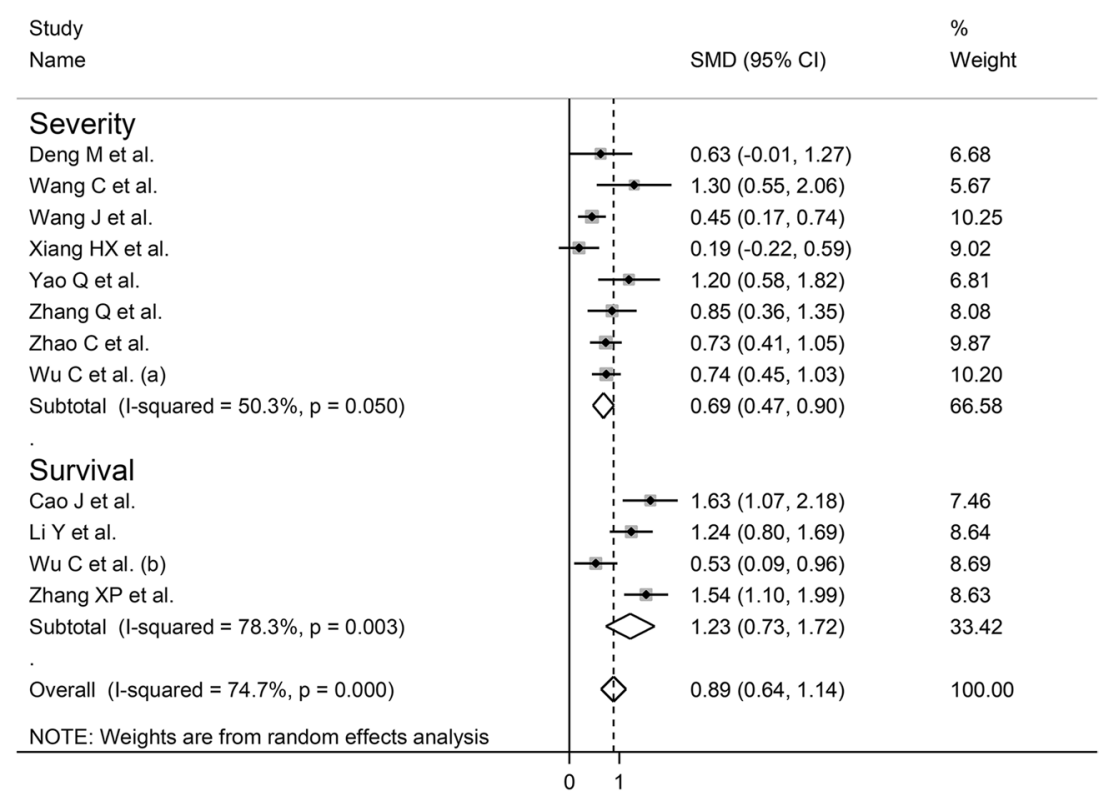


important pathophysiological role in the immunomodulatory responses observed during inflammatory states and infections [19]. Furthermore, its production can be modulated by several cytokines [19]. Consequently, fluctuations in serum cystatin $\mathrm{C}$ concentrations can be associated not only with changes in glomerular filtration rate but also with alterations in its production and/or consumption [19]. In turn, cystatin $\mathrm{C}$ can modulate the release of a number of cytokines, e.g., tumour necrosis factor- $\alpha$, interleukin-12, and interleukin-10, as well as nitric oxide (NO) [19]. In particular, cystatin C activates the inducible isoform of NO synthase (iNOS), which is primarily responsible for the excessive NO production observed in local and systemic proinflammatory states [48]. This leads to the generation of highly reactive NO derivatives, nitrosative stress and irreversible modifications of several intracellular components, with consequent cell apoptosis and organ dysfunction. These phenomena play an important role in the pathophysiology of the cytokine storm and severe COVID-19, and the associated multi-organ compromise observed in these patients [3, 49]. There is also evidence that cystatin $\mathrm{C}$ can exert antiviral effects. Studies have shown that cystatin $\mathrm{C}$ can inhibit the replication of human coronaviruses other than SARS-CoV-2 in human lung cells, poliovirus, adenovirus, and herpes simplex virus [50-53]. Taken together, these data support the proposition that elevations in serum cystatin $\mathrm{C}$ concentrations in severe COVID-19 may reflect the presence of one or more coexisting processes, including reduced renal function, excessive release of pro-inflammatory cytokines, anti-viral effects, iNOS-mediated stimulation of NO synthesis, and cytokine storm. Notably, our meta-regression did not show any significant association between the SMD of cystatin C concentrations and markers of inflammation and renal function. This suggests that the information provided by cystatin $\mathrm{C}$ is complementary to that of conventional markers of renal function and inflammation, rather than redundant.

The extreme between-study heterogeneity observed in our meta-analysis represents a significant limitation that curtails the generalizability of the results. However, the trend and magnitude of the reported differences in cystatin $\mathrm{C}$ were maintained, in the presence of reduced heterogeneity $\left(I^{2}=50.3 \%, p=0.05\right)$, in a sub-group of eight studies that had disease severity as endpoint. It is possible that other, unreported factors might have contributed to this residual heterogeneity. One such factor is the inter-laboratory difference in cystatin $\mathrm{C}$ assay measurement, which can involve nephelometric, turbidimetric, or spectrophotometric immunoassays [54-56]. At the same time, there was no evidence of publication bias and the overall effect size was not affected in sensitivity analysis. Another limitation is that no selected study, barring one [34], performed a serial measurement of complement component concentrations during hospitalization. This might provide additional information regarding possible clinical deterioration. Further studies are required to determine whether serial measurements of cystatin $\mathrm{C}$ provide additional prognostic information to that of single measurements on admission.

In conclusion, our systematic review and meta-analysis with meta-regression has shown that higher serum concentrations of cystatin $\mathrm{C}$, indicating one or more processes including deterioration of renal function, excess inflammation, anti-viral activity, and cytokine storm, are associated with severe disease and increased mortality in hospitalized patients with COVID-19. Additional studies are required to determine whether single or serial measurement of this biomarker, with or without other clinical, demographic, and biochemical variables, can further enhance early risk stratification and clinical decisions in this patient group.

Author contributions Initial idea: AZ; Data analysis: AZ; Data interpretation: AZ, AAM; First draft: AA Mangoni; Subsequent drafts and final version: AZ, AAM.

Funding This study was supported by a Visiting Professorship awarded to Arduino A Mangoni by the University of Sassari.

Data availability The data that support the findings of this systematic review and meta-analysis with meta-regression are available from Angelo Zinellu upon reasonable request.

Code availability Not applicable.

\section{Declarations}

Conflict of interest The authors declare no financial or non-financial conflicts of interest for this work.

Ethical approval No ethics approval was required as this study was a systematic review and meta-analysis of published work.

\section{References}

1. Huang C, Soleimani J, Herasevich S, Pinevich Y, Pennington KM, Dong Y, Pickering BW, Barwise AK (2021) Clinical characteristics, treatment, and outcomes of critically Ill patients with COVID-19: a scoping review. Mayo Clin Proc 96:183-202. https://doi.org/10.1016/j.mayocp.2020.10.022

2. Pijls BG, Jolani S, Atherley A, Derckx RT, Dijkstra JIR, Franssen GHL, Hendriks S, Richters A, Venemans-Jellema A, Zalpuri S, Zeegers MP (2021) Demographic risk factors for COVID-19 infection, severity, ICU admission and death: a meta-analysis of 59 studies. BMJ Open 11:e044640. https://doi.org/10.1136/bmjop en-2020-044640

3. Fajgenbaum DC, June CH (2020) Cytokine storm. N Engl J Med 383:2255-2273. https://doi.org/10.1056/NEJMra2026131

4. Paliogiannis P, Zinellu A, Scano V, Mulas G, De Riu G, Pascale RM, Arru LB, Carru C, Pirina P, Mangoni AA, Fois AG (2020) Laboratory test alterations in patients with COVID-19 and non COVID-19 interstitial pneumonia: a preliminary report. J Infect Dev Ctries 14:685-690. https://doi.org/10.3855/jidc.12879 
5. Gao YD, Ding M, Dong X, Zhang JJ, Kursat Azkur A, Azkur D, Gan H, Sun YL, Fu W, Li W, Liang HL, Cao YY, Yan Q, Cao C, Gao HY, Bruggen MC, van de Veen W, Sokolowska M, Akdis M, Akdis CA (2021) Risk factors for severe and critically ill COVID-19 patients: a review. Allergy 76:428-455. https://doi. org/10.1111/all.14657

6. Zinellu A, Paliogiannis P, Carru C, Mangoni AA (2021) Serum amyloid A concentrations, COVID-19 severity and mortality: an updated systematic review and meta-analysis. Int J Infect Dis. https://doi.org/10.1016/j.ijid.2021.03.025

7. Zinellu A, Mangoni AA (2021) Serum prealbumin concentrations, COVID-19 severity, and mortality: a systematic review and meta-analysis. Front Med (Lausanne) 8:638529. https://doi.org/ 10.3389/fmed.2021.638529

8. Thakur V, Ratho RK, Kumar P, Bhatia SK, Bora I, Mohi GK, Saxena SK, Devi M, Yadav D, Mehariya S (2021) Multi-organ involvement in COVID-19: beyond pulmonary manifestations. J Clin Med. https://doi.org/10.3390/jcm10030446

9. Farouk SS, Fiaccadori E, Cravedi P, Campbell KN (2020) COVID-19 and the kidney: what we think we know so far and what we don't. J Nephrol 33:1213-1218. https://doi.org/10.1007/ s40620-020-00789-y

10. Nadim MK, Forni LG, Mehta RL, Connor MJ Jr, Liu KD, Ostermann M, Rimmele T, Zarbock A, Bell S, Bihorac A, Cantaluppi V, Hoste E, Husain-Syed F, Germain MJ, Goldstein SL, Gupta S, Joannidis M, Kashani K, Koyner JL, Legrand M, Lumlertgul N, Mohan S, Pannu N, Peng Z, Perez-Fernandez XL, Pickkers P, Prowle J, Reis T, Srisawat N, Tolwani A, Vijayan A, Villa G, Yang L, Ronco C, Kellum JA (2020) COVID-19-associated acute kidney injury: consensus report of the 25th acute disease quality initiative (ADQI) workgroup. Nat Rev Nephrol 16:747-764. https://doi.org/10.1038/s41581-020-00356-5

11. Paliogiannis P, Mangoni AA, Dettori P, Nasrallah GK, Pintus G, Zinellu A (2020) D-Dimer concentrations and COVID-19 severity: a systematic review and meta-analysis. Front Public Health 8:432. https://doi.org/10.3389/fpubh.2020.00432

12. Giordo R, Paliogiannis P, Mangoni AA, Pintus G (2021) SARSCoV-2 and endothelial cell interaction in COVID-19: molecular perspectives. Vasc Biol 3:R15-R23. https://doi.org/10.1530/ VB-20-0017

13. Su H, Yang M, Wan C, Yi LX, Tang F, Zhu HY, Yi F, Yang HC, Fogo AB, Nie X, Zhang C (2020) Renal histopathological analysis of 26 postmortem findings of patients with COVID-19 in China. Kidney Int 98:219-227. https://doi.org/10.1016/j.kint.2020.04. 003

14. Puelles VG, Lutgehetmann M, Lindenmeyer MT, Sperhake JP, Wong MN, Allweiss L, Chilla S, Heinemann A, Wanner N, Liu S, Braun F, Lu S, Pfefferle S, Schroder AS, Edler C, Gross O, Glatzel M, Wichmann D, Wiech T, Kluge S, Pueschel K, Aepfelbacher M, Huber TB (2020) Multiorgan and renal tropism of SARS-CoV-2. N Engl J Med 383:590-592. https://doi.org/10.1056/NEJMc20114 00

15. Rossi GM, Delsante M, Pilato FP, Gnetti L, Gabrielli L, Rossini G, Re MC, Cenacchi G, Affanni P, Colucci ME, Picetti E, Rossi S, Parenti E, Maccari C, Greco P, Di Mario F, Maggiore U, Regolisti G, Fiaccadori E (2020) Kidney Biopsy findings in a critically Ill COVID-19 patient with dialysis-dependent acute kidney injury: a case against "SARS-CoV-2 nephropathy." Kidney Int Rep 5:11001105. https://doi.org/10.1016/j.ekir.2020.05.005

16. Kar S, Paglialunga S, Islam R (2018) Cystatin $C$ is a more reliable biomarker for determining eGFR to support drug development studies. J Clin Pharmacol 58:1239-1247. https://doi.org/10.1002/ jcph. 1132

17. Filler G, Bokenkamp A, Hofmann W, Le Bricon T, MartinezBru C, Grubb A (2005) Cystatin C as a marker of GFR-history, indications, and future research. Clin Biochem 38:1-8. https://doi. org/10.1016/j.clinbiochem.2004.09.025

18. Herget-Rosenthal S, Bokenkamp A, Hofmann W (2007) How to estimate GFR-serum creatinine, serum cystatin $\mathrm{C}$ or equations? Clin Biochem 40:153-161. https://doi.org/10.1016/j.clinbiochem. 2006.10 .014

19. Zi M, Xu Y (2018) Involvement of cystatin $\mathrm{C}$ in immunity and apoptosis. Immunol Lett 196:80-90. https://doi.org/10.1016/j. imlet.2018.01.006

20. Werle B, Sauckel K, Nathanson CM, Bjarnadottir M, Spiess E, Ebert W, Abrahamson M (2003) Cystatins C, E/M and F in human pleural fluids of patients with neoplastic and inflammatory lung disorders. Biol Chem 384:281-287. https://doi.org/10.1515/BC. 2003.031

21. Wells GA, Shea B, O'Connell D, Peterson J, Welch V, Losos M, Tugwell P (2013) The Newcastle-Ottawa Scale (NOS) for assessing the quality of nonrandomised studies in meta-analyses. http:// www.ohri.ca/programs/clinical_epidemiology/oxford.asp.

22. Wan X, Wang W, Liu J, Tong T (2014) Estimating the sample mean and standard deviation from the sample size, median, range and/or interquartile range. BMC Med Res Methodol 14:135. https://doi.org/10.1186/1471-2288-14-135

23. Bowden J, Tierney JF, Copas AJ, Burdett S (2011) Quantifying, displaying and accounting for heterogeneity in the meta-analysis of RCTs using standard and generalised Q statistics. BMC Med Res Methodol 11:41. https://doi.org/10.1186/1471-2288-11-41

24. Higgins JP, Thompson SG (2002) Quantifying heterogeneity in a meta-analysis. Stat Med 21:1539-1558. https://doi.org/10.1002/ sim. 1186

25. Tobias A (1999) Assessing the influence of a single study in the meta-analysis estimate. Stata Tech Bulletin 47:15-17

26. Begg CB, Mazumdar M (1994) Operating characteristics of a rank correlation test for publication bias. Biometrics 50:1088-1101

27. Sterne JA, Egger M (2001) Funnel plots for detecting bias in meta-analysis: guidelines on choice of axis. J Clin Epidemiol 54:1046-1055. https://doi.org/10.1016/s0895-4356(01)00377-8

28. Duval S, Tweedie R (2000) Trim and fill: a simple funnel-plotbased method of testing and adjusting for publication bias in metaanalysis. Biometrics 56:455-463. https://doi.org/10.1111/j.0006341x.2000.00455.x

29. Liberati A, Altman DG, Tetzlaff J, Mulrow C, Gotzsche PC, Ioannidis JP, Clarke M, Devereaux PJ, Kleijnen J, Moher D (2009) The PRISMA statement for reporting systematic reviews and meta-analyses of studies that evaluate healthcare interventions: explanation and elaboration. BMJ 339:b2700. https://doi.org/10. 1136/bmj.b2700

30. Cao J, Tu WJ, Cheng W, Yu L, Liu YK, Hu X, Liu Q (2020) Clinical features and short-term outcomes of 102 patients with coronavirus disease 2019 in Wuhan, China. Clin Infect Dis 71:748-755. https://doi.org/10.1093/cid/ciaa243

31. Deng M, Qi Y, Deng L, Wang H, Xu Y, Li Z, Meng Z, Tang J, Dai $Z$ (2020) Obesity as a potential predictor of disease severity in young COVID-19 patients: a retrospective study. Obesity (Silver Spring) 28:1815-1825. https://doi.org/10.1002/oby.22943

32. Li Y, Yang S, Peng D, Zhu HM, Li BY, Yang X, Sun XL, Zhang M (2020) Predictive value of serum cystatin C for risk of mortality in severe and critically ill patients with COVID-19. World J Clin Cases 8:4726-4734. https://doi.org/10.12998/wjcc.v8.i20.4726

33. Tang Y, Li Y, Sun J, Pan H, Yao F, Jiao X (2020) Selection of an optimal combination panel to better triage COVID-19 hospitalized patients. J Inflamm Res 13:773-787. https://doi.org/10.2147/JIR. S273193

34. Wang C, Deng R, Gou L, Fu Z, Zhang X, Shao F, Wang G, Fu W, Xiao J, Ding X, Li T, Xiao X, Li C (2020) Preliminary study to identify severe from moderate cases of COVID-19 using 
combined hematology parameters. Ann Transl Med 8:593. https:// doi.org/10.21037/atm-20-3391

35. Wang J, Guo S, Zhang Y, Gao K, Zuo J, Tan N, Du K, Ma Y, Hou Y, Li Q, Xu H, Huang J, Huang Q, Na H, Wang J, Wang X, Xiao Y, Zhu J, Chen H, Liu Z, Wang M, Zhang L, Wang W (2020) Clinical features and risk factors for severe inpatients with COVID-19: a retrospective study in China. PLoS ONE 15:e0244125. https:// doi.org/10.1371/journal.pone.0244125

36. Wu C, Chen X, Cai Y, Xia J, Zhou X, Xu S, Huang H, Zhang L, Zhou X, Du C, Zhang Y, Song J, Wang S, Chao Y, Yang Z, Xu J, Zhou X, Chen D, Xiong W, Xu L, Zhou F, Jiang J, Bai C, Zheng J, Song Y (2020) Risk factors associated with acute respiratory distress syndrome and death in patients with coronavirus disease 2019 pneumonia in Wuhan, China. JAMA Intern Med 180:934943. https://doi.org/10.1001/jamainternmed.2020.0994

37. Xiang HX, Fei J, Xiang Y, Xu Z, Zheng L, Li XY, Fu L, Zhao H (2021) Renal dysfunction and prognosis of COVID-19 patients: a hospital-based retrospective cohort study. BMC Infect Dis 21:158. https://doi.org/10.1186/s12879-021-05861-x

38. Yang Z, Shi J, He Z, Lu Y, Xu Q, Ye C, Chen S, Tang B, Yin K, Lu Y, Chen X (2020) Predictors for imaging progression on chest CT from coronavirus disease 2019 (COVID-19) patients. Aging (Albany NY) 12:6037-6048. https://doi.org/10.18632/aging. 102999

39. Yao Q, Wang P, Wang X, Qie G, Meng M, Tong X, Bai X, Ding M, Liu W, Liu K, Chu Y (2020) A retrospective study of risk factors for severe acute respiratory syndrome coronavirus 2 infections in hospitalized adult patients. Pol Arch Intern Med 130:390-399. https://doi.org/10.20452/pamw.15312

40. Zhang Q, Wei Y, Chen M, Wan Q, Chen X (2020) Clinical analysis of risk factors for severe COVID-19 patients with type 2 diabetes. J Diabetes Complications 34:107666. https://doi.org/10. 1016/j.jdiacomp.2020.107666

41. Zhang XB, Hu L, Ming Q, Wei XJ, Zhang ZY, Chen LD, Wang MH, Yao WZ, Huang QF, Ye ZQ, Cai YQ, Zeng HQ (2021) Risk factors for mortality of coronavirus disease-2019 (COVID-19) patients in two centers of Hubei province, China: a retrospective analysis. PLoS ONE 16:e0246030. https://doi.org/10.1371/journ al.pone. 0246030

42. Zhao C, Bai Y, Wang C, Zhong Y, Lu N, Tian L, Cai F, Jin R (2021) Risk factors related to the severity of COVID-19 in Wuhan. Int J Med Sci 18:120-127. https://doi.org/10.7150/ijms.47193

43. Cohen J (1988) Statistical power analysis for the behavioral sciences, 2nd edn. Erlbaum

44. Tangri N, Stevens LA, Schmid CH, Zhang YL, Beck GJ, Greene T, Coresh J, Levey AS (2011) Changes in dietary protein intake has no effect on serum cystatin $\mathrm{C}$ levels independent of the glomerular filtration rate. Kidney Int 79:471-477. https://doi.org/10. 1038/ki.2010.431

45. Baxmann AC, Ahmed MS, Marques NC, Menon VB, Pereira AB, Kirsztajn GM, Heilberg IP (2008) Influence of muscle mass and physical activity on serum and urinary creatinine and serum cystatin C. Clin J Am Soc Nephrol 3:348-354. https://doi.org/10.2215/ CJN.02870707
46. Mazur MJ, Heilman RL (2005) Early detection of acute renal failure by serum cystatin C: a new opportunity for a hepatologist. Liver Transpl 11:705-707. https://doi.org/10.1002/lt.20422

47. Ishibashi Y, Yamauchi M, Musha H, Mikami T, Kawasaki K, Miyake F (2010) Impact of contrast-induced nephropathy and cardiovascular events by serum cystatin $\mathrm{C}$ in renal insufficiency patients undergoing cardiac catheterization. Angiology 61:724 730. https://doi.org/10.1177/0003319710379108

48. Anavi S, Tirosh O (2020) iNOS as a metabolic enzyme under stress conditions. Free Radic Biol Med 146:16-35. https://doi. org/10.1016/j.freeradbiomed.2019.10.411

49. Karki R, Sharma BR, Tuladhar S, Williams EP, Zalduondo L, Samir P, Zheng M, Sundaram B, Banoth B, Malireddi RKS, Schreiner P, Neale G, Vogel P, Webby R, Jonsson CB, Kanneganti TD (2021) Synergism of TNF-alpha and IFN-gamma triggers inflammatory cell death, tissue damage, and mortality in SARS-CoV-2 infection and cytokine shock syndromes. Cell 184(149-68):e17. https://doi.org/10.1016/j.cell.2020.11.025

50. Collins AR, Grubb A (1991) Inhibitory effects of recombinant human cystatin $\mathrm{C}$ on human coronaviruses. Antimicrob Agents Chemother 35:2444-2446. https://doi.org/10.1128/aac.35.11.2444

51. Korant BD, Brzin J, Turk V (1985) Cystatin, a protein inhibitor of cysteine proteases alters viral protein cleavages in infected human cells. Biochem Biophys Res Commun 127:1072-1076. https://doi. org/10.1016/s0006-291x(85)80054-1

52. Ruzindana-Umunyana A, Weber JM (2001) Interactions of human lacrimal and salivary cystatins with adenovirus endopeptidase. Antiviral Res 51:203-214. https://doi.org/10.1016/s01663542(01)00154-1

53. Gu M, Haraszthy GG, Collins AR, Bergey EJ (1995) Identification of salivary proteins inhibiting herpes simplex virus 1 replication. Oral Microbiol Immunol 10:54-59. https://doi.org/10.1111/j. 1399-302x.1995.tb00118.x

54. Delanaye P, Pieroni L, Abshoff C, Lutteri L, Chapelle JP, Krzesinski JM, Hainque B, Cavalier E (2008) Analytical study of three cystatin $\mathrm{C}$ assays and their impact on cystatin C-based GFR-prediction equations. Clin Chim Acta 398:118-124. https://doi.org/ 10.1016/j.cca.2008.09.001

55. Hossain MA, Emara M, El Moselhi H, Shoker A (2009) Comparing measures of cystatin $\mathrm{C}$ in human sera by three methods. Am J Nephrol 29:381-391. https://doi.org/10.1159/000168486

56. White CA, Rule AD, Collier CP, Akbari A, Lieske JC, Lepage N, Doucette S, Knoll GA (2011) The impact of interlaboratory differences in cystatin $\mathrm{C}$ assay measurement on glomerular filtration rate estimation. Clin J Am Soc Nephrol 6:2150-2156. https://doi. org/10.2215/CJN.00130111

Publisher's Note Springer Nature remains neutral with regard to jurisdictional claims in published maps and institutional affiliations. 